\title{
MY INSTRUCTOR MADE ME DO IT: TASK CHARACTERISTICS OF PROCRASTINATION
}

David S. Ackerman, California State University Northridge, College of Business and Economics, Northridge, CA 91330-8377; (818) 677-4628

Barbara L. Gross, California State University Northridge, College of Business and Economics, Northridge, CA 91330-8377; (818) 677-4634

\section{ABSTRACT}

Studies have found procrastination to affect most undergraduate students regardless of ethnicity, age, or gender (e.g., Kachgal et al. 2001). Though procrastination may relieve stress in the short-term, it also causes stress. Students worry about their own procrastination, and are left feeling anxious, guilty, and even more pressured (Pychyl et al. 2000). Procrastination can lead to serious consequences because it compromises one's ability to set and achieve personal, academic, and career goals.

Burka and Yuen (1990) characterized procrastination as a way of expressing internal conflict and protecting a vulnerable sense of self-esteem. A wide range of behavioral, affective, and cognitive factors have been identified as contributing to procrastination, including lack of motivation, deficient self-regulation, external locus of control, perfectionism, trait and state anxiety, fear of failure, low self-efficacy, and low selfconfidence (cf Haycock et al. 1998). Solomon and Rothblum (1984) found that students' explanations for their own procrastination were related to fear of failure, taking on such specific forms as performance anxiety, perfectionism, and lack of self-confidence.

In contrast to previous research which has focused on personal factors associated with procrastination, the study reported in this paper focuses on characteristics of a task or assignment that might influence procrastination. Selected assignment and course characteristics suggested by Paden and Stell (1997) were examined. Specifically, the study compared the characteristics of a particular critical incident assignment chosen by individual students based on whether each student reported more or less procrastination on the assignment.

Students in marketing courses were asked to think about an important assignment they had completed during the previous semester. They were then asked to fill out a questionnaire about procrastination on the assignment and about various assignment-related variables. Altogether 159 students participated, resulting in 155 usable questionnaires.
Several of the factors from Paden and Stell's (1997) model were found to be significant. As predicted, the low procrastination group reported more interest in the assignment than did those who procrastinated more. Less procrastination also was associated with clarity of instructions, and with rewards or incentives for getting an early start. Lastly, less procrastination was reported when interdependence had been built into the course structure. However, norms in a class, perceived difficulty, and time required to finish an assignment did not vary between the high and low procrastination groups.

\section{REFERENCES}

Burka, Jane B., and Lenora M. Yuen. 1990. Procrastination: Why you do it, what to do about it. $2^{\text {nd }}$ ed. New York: Prentice Hall.

Haycock, Laurel A., Patricia McCarthy, and Carol L. Skay. 1998. Procrastination in college students: The role of self-efficacy and anxiety. Journal of Counseling and Development 76 (Summer): 317 324.

Kachgal, Mera M., L. Sunny Hansen, and Kevin J. Nutter. 2001. Academic procrastination prevention/intervention strategies and recommendations. Journal of Developmental Education 25 (Fall): 14-24.

Paden, Nita, and Roxanne Stell. 1997. Reducing procrastination through assignment and course design. Marketing Education Review 7 (Summer): 17-25.

Pychyl, Timothy A., Johnathan M. Lee, Rachelle Thibodeau, and Allan Blunt. 2000. Five days of emotion: An experience sampling study of undergraduate student procrastination. Journal of Social Behavior and Psychology 15 (5): 239-254.

Soloman, L. J. and E. D. Rothblum. 1984. Academic procrastination: Frequency and cognitive-behavioral correlates. Journal of Counseling Psychology 31 (4): $503-509$. 